\title{
Großartiges erleben und sich dabei noch fortbilden
}

\begin{abstract}
Weit weg vom Großstadttrubel und in einer einzigartigen Lage inmitten unberührter Natur liegt Schloss Elmau. Hier können Zahnärzte vom 22. bis 25. November 2017 übernachten und eine intensive Schulung im Bereich Notfalltraining erleben. Die Fortbildung leiten Dr. Heribert Königer, Zahnarzt und Arzt sowie Notarzt der Bergwacht, und die Ärztin Barbara Spohn-Königer aus Mittenwald. Beide sind Notfallexperten und vermitteln Notfallsituationen praxisorientiert und professionell.
\end{abstract}

Die Kursinhalte des intensiven Notfalltrainings umfassen: Herz-Lungen-Wiederbelebung, Intubation an der Übungspuppe, Messung des Blutdrucks, Blutzuckertest, Infusionstraining am Phantomarm, Koniotomie am Simulator sowie Fallszenarien. Im theoretischen Teil werden Notfallausrüstung und Notfallmedikamente besprochen. Für dieses Seminar gibt es 37 Fortbildungspunkte.

\section{Sport und Entspannung}

Neben dem Seminar sind zahlreiche sportliche Aktivitäten in der Hochgebirgslandschaft des Karwendel möglich, zum Beispiel Trekking-Touren im einsamen Hochgebirge, das Durchwandern der Geisterklamm oder Rafting auf der grünen Isar. Ein Besuch im Klettergarten mit Abseilübungen verschiedener Schwierigkeitsgrade steht ebenfalls auf dem Programm. Die sportlichen Angebote sind kein Muss, aber durchweg für Anfänger geeignet und auf freiwilliger Basis. Für entsprechende Sicherheitsausstattung ist gesorgt.

Geselligkeit und die Möglichkeit zum Relaxen kommen aber auch nicht zu kurz. Schloss Elmau ist für seine beinahe täglichen Hauskonzerte oder Literaturevents berühmt. Auch das vielfach ausgezeichnete Spa Wellness-Angebot auf Schloss Elmau lässt keine Wünsche offen. Die Nutzung der Wellnesseinrichtungen sowie der Besuch der kulturellen Veranstaltungen sind im Hotelzimmerpreis inbegriffen.

Die Teilnahmegebühr beträgt 1.950 Euro pro Person im Einzel- oder Doppelzimmer. Der Gesamtpreis umfasst sowohl das Notfallseminar als auch drei Übernachtungen auf Schloss Elmau, Frühstücksbuffet, Abendessen mit Dine-Around-Gut- schein in Höhe bis zu 50 Euro (Schloss-Elmau-Pauschale), Kurtaxe, die angebotenen Aktivitäten und Sicherheitsausstattung. Nicht eingeschlossen sind An- und Abreise sowie zusätzlicher Verzehr oder selbst dazugebuchte Leistungen.

Anmeldungen unter: Freier Verband Deutscher Zahnärzte e.V., Mallwitzstr. 16, 53177 Bonn, Telefon 0228-8557-0, Fax 0228-34 06 71, E-Mail: akadmie@fvdz.de.

$c t$

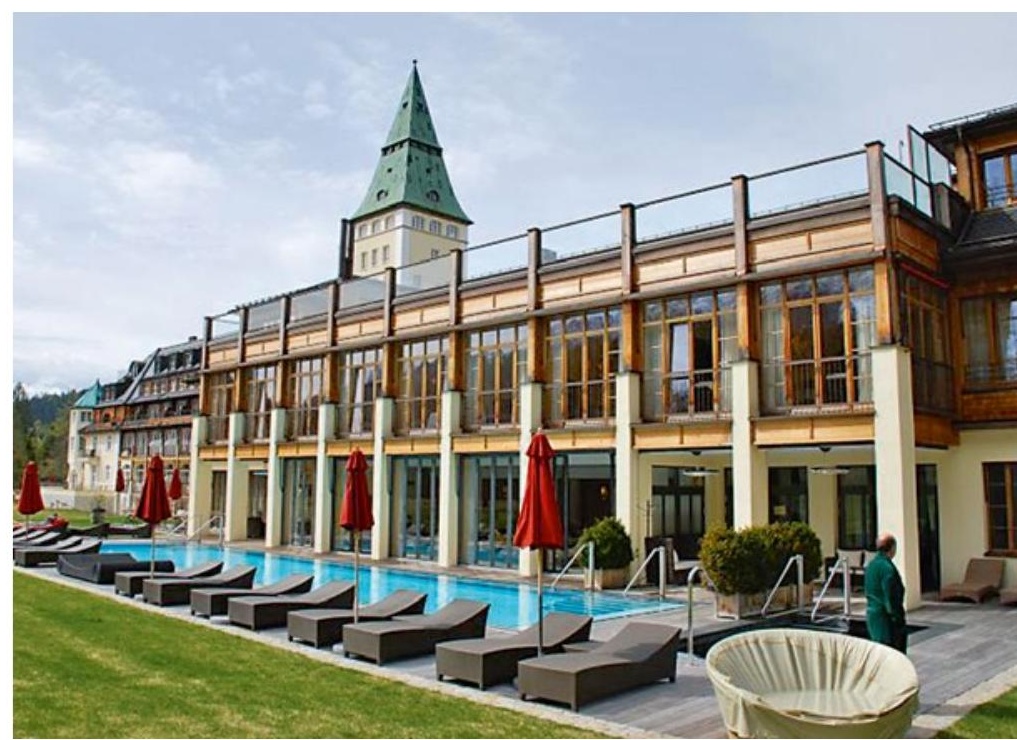

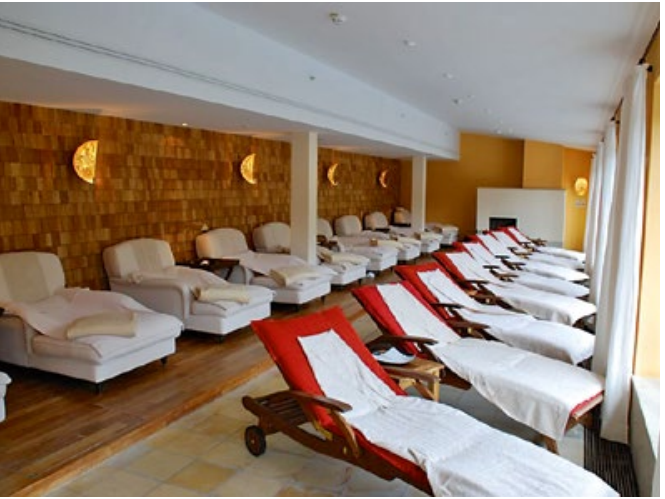
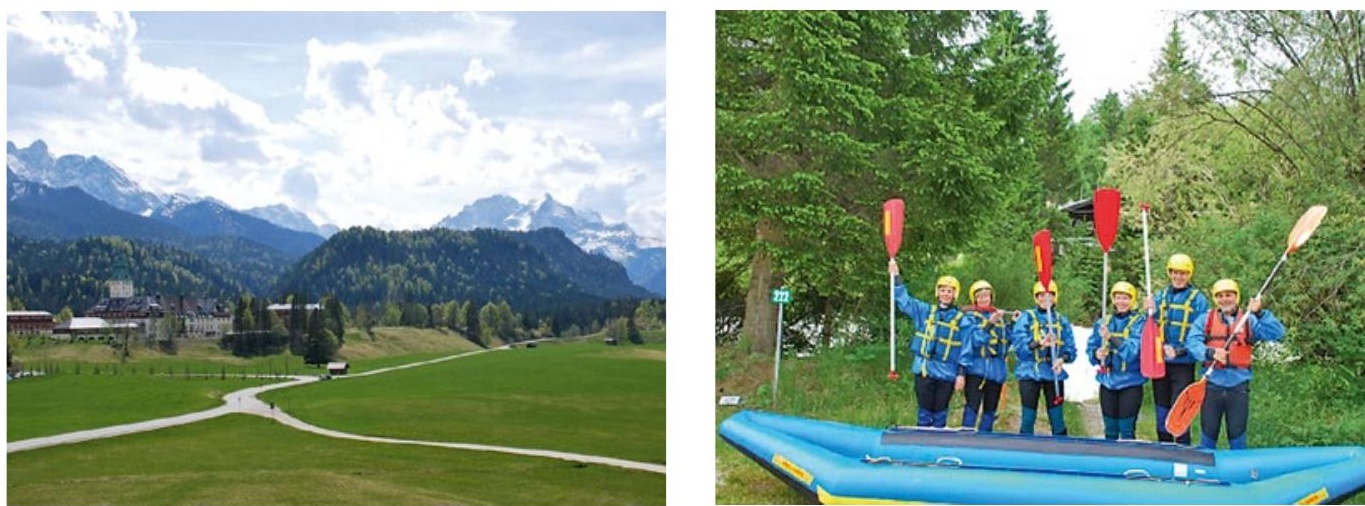